Some meteorologists have asserted that the south-west monsoon may be considered a stationary cyclone. This might be so if we define a cyclone simply as an irregularly circular area of low pressure round and into which the wind blows spirally. But when we look at the kind of rain and varieties of cloud which give distinctive character to various parts of a cyclone, our own observations and the information we have received from others entirely discountenance this idea.

In Malaysia, between Singapore and Borneo, in the early days of April the surface-winds were all from about north-east, and the clouds at various levels always from more south of east. In North Borneo, later in the month, the south-west land breeze of the morning always went round by south-east to north-east in the afternoon and evening, while the higher clouds came always from about north-east.

In Sooloo and the Philippines during the month of May the surface winds were much complicated by land and sea breezes, but the sequence of upper currents was always that proper to the hemisphere.

So far for ordinary weather. I was not fortunate enough to meet with a typhoon, but the reports of the observatories at Manilla, Hong Kong, and Tokio are all agreed that the relation of upper and lower currents is the same in a typhoon in the China Seas as in a European cyclone.

Yokohama, June I 2

\section{RaLPH ABERCROMby}

\section{Mock Sun}

I INCLOSE sketch of the first mock sun I have been fortunate enough to see at Cranbrook, Kent, on July 20,5 to $5 \frac{1}{2}$ p.m.

About rom. before noticing this fine phenomenon we had noticed a fragment of it, not knowing what was to follow ; and we were struck by the extraordinary position of the bow with reference to the sun, viz, about $45^{\circ}$ from it, and at an unaccountable angle to the horizon. The latter picture I can only draw by memory. The upper drawing is from one made on the spot in presence of two intelligent adult witnesses, who were consulted on each point which I proceed to notice.

(I) The rainbow near the zenith was of the breadth and brilliancy of an ordinary rainbow (the same was the case with the fragment seen ten minutes earlier, which was lost when the rest came out). The fact of the arc seen near the zenith belonging to two circles, one small and one large, touching each other, was sufficiently certain to my eye, confirmed by another educated eye, but not admitted by the third less educated one. I draw it as I apprehended it. The colours were unusually vivid against a thin veil of fleecy clouds.

(2) The halo-circle round the sun, and the arched eyebrows, so to call them, were about half the breadth of the rainbow, and washy in colour. The shapes drawn are quite faithful, and were so sharp as to leave no room whatever for doubt or imagination.

(3) The interior area of the circle was darker than the ouside.

(4) The position of the mock sun was not diametrical. The sun, seen through a handkerchief whose edge was stretched through the two mocks, was about two-thirds of its own breadth below the edge, clear.

(5) The white rays (about half the breadth of the mock lights) were seldom seen both at the same time, but were quite decided outside the circle and traceable within it, but nowhere nearly so bright as the mock lights.

(6) The mock lights were short fragments of arcs of rainbows, more vividly coloured than the halo-circle outside of which they stood clear of it, but not so broad and not quite so vivid as the great rainbow arc.

These fragments were not tangential. Short as they were, their own axis was clearly determined by all three witnesses to be inclined towards the radial ray, and more inclined to the arc of the halo. But I have unconsciously given a curved shape to the short fragment. It was too short to show a curve. There was no pretence of a disk, as if really a mock sun. It was only a very vivid fragment of a rainbow. A third fainter one was at the top of the halo.

The sky was much covered with thin cirrus; a fine sunny evening; air peculiarly clear for distant views.

Collingwood, July 22

W. J. HERSCHEL

P.S.-Radius of halo-circle, measured as best I conld, $22^{\frac{1}{2}}$ $\pm 2 \frac{1}{2}^{\circ}$. Radius, continued to the rainbow, $45^{\circ}$ with proportionate error. The arc of the halo-circle was generally absent next to the mock lights, but could sometimes be traced.
"The Duration of Germ-Life in Water"

IN a letter bearing this title in your last issue (p. 265) Mr Downes refers to the recent publication by Messrs. Crookes, Odling, and Tidy, of some experiments which they have made on the vitality of the Bacillus anthracis in water, with regard to which I should like to call attention to the fact that this subject has during the past three years been investigated by various experimenters, including Koch, Cornil, and Babes, Nicati and Rietsch. Within the past two months no less than three papers have been published on this subject, two of them in Germany by Dr. Wolfhügel and Meade Bolton respectively, whilst the third, by myself, "On the Multiplication of Micro-organisms," was communicated to the Royal Society at the meeting in June last. In this paper $I$ have recorded a number of experiments made both with the mixtures of organisms found in various natural waters, as well as with three well-characterised forms which are associated with disease, viz. Koch's "Comma" spirillum of A siatic cholera, Finkler-Prior's "Comma" spirillum of European cholera, and the Bacillus pyocyaneus, which produces the greenish-blue colouring matter frequently present in abscesses. The methods of research which have been independently selected both by Wolfbuigel, Meade Bolton, and myself, are identical, and consist in the examination, by gelatine platecultivation, of waters puroosely impregnated with the organisms in question. This method is obviously the one which most recommends itself for the purpose, as it not only enables one to ascertain the presence or absence of the organisms, but also to quantitatively follow their multiplication or reduction. I may mention that these three organisms present great differences in their behaviour under similar circumstances; thus the Bacillus pyocyaneus is possessed of far greater vitality in water than either of the other two, its presence being demonstrable even in distilled water after fifty-three days, in numbers exceeding manyfold those originally introduced. Koch's "Comma" spirillum, on the other hand, was in the purest forms of potable water no longer demonstrable after the ninth day, whilst in London sewage it was found in largely multiplied numbers after twentynine days; whilst Finkler's spirillum conld in no case be detected after the first day, and frequently not even on the day of inoculation. A curious phenomenon, which my experiments, as well as those of Wolf hiigel and Meade Bolton have brought to light, is that when organisms of this kind, which are not the natural inhabitants of water, are introduced into this medium, a large proportion of them are frequently at first destroyed, a greater or less multiplication in their numbers often subsequently taking place.

The Bacillus anthracis, as is well known to bacteriologists, appears in two very distinct forms, the bacillus-form and the spore-form, and these present very great differences in their powers of endurance, the former being destroyed with comparative ease, whilst the spores are iemarkable for their vitality. Mr. Crookes and his colleagues have apparently experimented with the bacillus-form of anthrax only, which they state is rapidly destroyed when introduced into London water, but Dr. Meade Bolton, who has dealt with anthrax in both its forms, has shown that the spores of anthrax retain their vitality even in distilled water for upwards of ninety days, and that it is only the bacilli which rapidly perish in some kinds of potable water. In polInted well-water Meade Bolton has also shown that even the bacilli are persistent for upwards of ninety days, and the spores for nearly a year, whilst Wolfhiigel has found that in polluted river-water (the River Panke, in Berlin), even when diluted tenfold with distilled water, the anthrax bacilli undergo extensive multiplication. Normal School of Science,

South Kensington Museum, S. W., July 26

\section{Animal Intelligence}

In NATURE for July $\mathbf{2 2}$, on p. $265, \mathrm{Mr}$. Frederick Lewis calls attention to a nest-building wasp who closed up her nest without filling it first with grubs or laying an egg. There is nothing uncommon in this neglect on the part of the wasp, as any one who has at all studied their habits in the tropics will know, such perfectly empty nests being frequently met with. I have often thought the empty nest might have something to do with the fact that the wasp may not have been prepared to deposit her egg; but then, if that were the case, we should occasionally find nests with the remains of the caterpillars or 